\title{
UMA BREVE DISCUSSÃO SOBRE ALGUNS CAMINHOS DA FÍSICA
}

\author{
Aurino Ribeiro Filho ${ }^{1}$
}

RESUMO: A interpretação dos fenômenos físicos sempre instigou a mente humana desde a antiguidade à contemporaneidade. Neste trabalho discutiremos, brevemente, o caminhar da física, tentando lembrar como os físicos conseguiram contribuir para o entendimento de fenômenos naturais, através de revoluções científicas que marcaram o pensamento científico e as tecnologias humanas (o mecanicismo, o eletromagnetismo, os quanta, as relatividades, o caos) até os nossos dias, em que despontam novos objetos físicos e novas teorias, a exemplo de: informação quântica, o emaranhamento quântico, teletransporte, descoerência, criptografia e computação quânticas, calibres, em que novas dificuldades de interpretação se fazem presentes mas não impedem a grande busca em torno do conhecimento científico.

PALAVRAS-CHAVE: Física; Ciência; Física Quântica; Teorias.

ABSTRACT: The interpretation of physical phenomena always instigated the human mind from antiquity to the contemporary times. In this paper we will discuss, briefly, the walk of physics 
trying to remember how physicists were able to contribute to the understanding of natural phenomena through scientific revolutions that marked the scientific thinking and human technologies (mechanism, electromagnetism, quanta, theories of relativity, chaos) until our days, in which emerge new physical objects and new theories, such as quantum information, entanglement, teleportation, decoherence, quantum computing and cryptography, gauges, in that new difficulties of interpretation are present but do not prevent the great search around the scientific knowledge

KEYWORDS: Physics; Science; Quantum Physics; Theories. 
A recente notícia da descoberta de mais uma partícula encantou os físicos e assombrou o mundo, em vista da possível confirmação de mais um triunfo da física teórica e matemática, através de mais um grande sucesso da alta tecnologia, representado pela construção e efetivação do LHC (Grande Colisor de Hádrons), o mais poderoso acelerador de partículas já construído, graças à cooperação de distintos cientistas, engenheiros e técnicos de diferentes países. Esta realização experimental talvez tenha conseguido comprovar um sonho de quase cinquenta anos -, a busca da partícula denominada - o bóson de Higgs. Mesmo se, por um acaso, tratarse de outra entidade, o fato em si evidencia o próprio trajeto das ciências e, em particular, da física, um exemplo de ciência cujos caminhos são longos e que, por uma tradição histórica, se iniciou na antiga Grécia, lá pelo século VI a.C. Naturalmente, não se pode esquecer as contribuições advindas de outras civilizações, às vezes ignoradas, pelos ocidentais, e não bem documentadas, $\mathrm{e}$ cujos avanços proporcionaram, em distintas épocas, a crença ou presunção de seu próprio fim, talvez por ingenuidade, de certos atores históricos, em propagarem que nada mais de relevante poderia ser acrescentado ao conhecimento da natureza, a não ser alguns resultados triviais.

Com esta breve introdução, a qual envolve a mais divulgada descoberta contemporânea desta ciência e a sua interligação comos tempos imemoriais, que a própria história nos indica, tentaremos relembrar, sucintamente, alguns caminhos e as possíveis teorias, que tentaram superar momentos críticos da ciência física, em que novos paradigmas (no sentido Kuhniano) surgiram e indicaram a necessidade de novos esforços, para a elucidação de novos fenômenos. Tudo isso interessa aos físicos, pois novos tópicos provocam a curiosidade e a busca de interpretações que relegam ou extrapolam antigos paradigmas (KUHN, 2006, p.20). 
Ao se discutir sobre o trabalho científico é interessante lembrar que o mesmo sempre manteve relações fortes com o trabalho filosófico. Ludovico Geymonat, em Dialética Científica e Liberdade, chama a atenção para as relações entre a ciência e a filosofia. Enfim, "ambas mergulham suas raízes no fato de ambas terem como objetivo aumentar os nossos conhecimentos" (GEYMONAT, 1986, p. 51). Alguns comentadores afirmam, com frequência, que a "ciência tem em vista o crescimento de nosso conhecimento em torno de argumentos particulares, enquanto a filosofia se ocupa, enfaticamente, de problemas gerais, por exemplo, das condições exigidas para se alcançar a verdade". É claro que esta distinção entre particular e geral é problemática - pergunta-se, por exemplo, "em que sentido é possível afirmar que a teoria da gravitação de Newton é um argumento particular, e também em que sentido é possível se afirmar que o cogito ergo sum de Descartes é um problema geral?" (ibidem, p 56).

O que se verifica, segundo Geymonat, é que a pretensão de se achar uma demarcação universalmente válida entre ciência e filosofia é ilusória, ambas "relacionam-se de diversas maneiras nas várias épocas da história, pois o significado dos conceitos de ciência e de filosofia sofre profundas modificações no decorrer do tempo". No caso da física, é interessante relembrar Redhead (1997, p.15) na sua discussão sobre a relação entre esta ciência e os filósofos da ciência. Para este autor, muitos físicos acham que "a filosofia, assim como a religião, está cheia de ismos e cismas, e é uma perda de tempo experimentá-los e organizá-los. É muito melhor trabalhar com persistência, e produzir uma boa física, do que se entregar a fantasia e especulação vãs". Por outro lado, alguns filósofos "consideram os físicos como indivíduos ingênuos, que fazem física de maneira acrítica, assemelhando-se à criança 
que anda de bicicleta, perfeitamente ignorante das sutilezas da dinâmica dos corpos rígidos!” (ibidem, p. 18).

No século XVII, o progresso e o desenvolvimento da ciência, em geral, e da física, em particular, foram bastante complexos. Foi naquele período que, pela primeira vez, a perspectiva científica tornou-se importante em comparação à do senso comum. Foi no mencionado século que a ciência começou a obter triunfos marcantes e a revelar uma perspectiva radicalmente distinta sobre certos aspectos fundamentais, em relação ao senso comum. Para o filósofo Bertrand Russell, o principal acontecimento no mencionado século, foi o divórcio entre percepção e matéria, assunto que interessou outros filósofos desde Descartes a Berkeley, levando este a negar a matéria, enquanto havia levado Leibniz, de fato, a negar a percepção. Nesse período marcante da história havia, basicamente, duas correntes, uma física seguidora da tradição científica fortemente matemática dos gregos. O texto grego Timeu, de Platão, é considerado como a primeira grande representação matemático-filosófica do universo. A outra corrente era seguidora da denominada ciência "baconiana" defendida por Francis Bacon (1561 - 1626), que recolhia muitos fatos advindos de experiências providas por artesãos, e mesmo por curiosos, àquela época.

A descoberta e a interpretação de fenômenos físicos sempre instigaram a mente dos humanos, desde a antiguidade até os nossos dias. No presente texto discutiremos algumas etapas importantes do caminhar da física, seguindo os passos de seus principais inquiridores, os físicos, sem termos a pretensão de completar o assunto. Não pretendemos seguir, rigorosamente, a cronologia dos distintos tópicos e sim focaremos nos aspectos mais essenciais e, por isso, será necessário omitir alguns assuntos e 
atores históricos. Serão destacadas algumas das principais teorias físicas, que caracterizam momentos importantes na história do pensamento humano.

\section{MUNDO ANTIGO, A FÍSICA CLÁSSICA E A MODERNIDADE}

De uma maneira intuitiva pode-se delimitar o início da física, a partir do surgimento da escrita, ou do nascimento da história, pois desde aqueles tempos surgiram registros de preocupações dos seres humanos, a respeito da gênese e do devir do universo. De acordo com os escribas de cada época, os primeiros "físicos" não tinham formação em física, a exemplo do que acontece nos nossos dias. Em verdade, eles eram geômetras, astrônomos e filósofos. O que poderia ser considerado pitoresco é que, nesses tempos imemoriais, esses personagens não eram também formados em universidades ou academias e, sim, em geral, eles eram mercadores, sacerdotes e governantes, todos curiosos e que demonstravam um forte interesse pelo conhecimento científico ao buscar elucidar vários fenômenos da natureza. Lima Vaz na apresentação do livro escrito por Braga (1991, p. 9) enfatiza:

"a física e a filosofia, como é sabido, confundem suas origens na aurora do pensamento grego, vêm a ser nas primeiras luzes da cultura ocidental. Não sem razão a doxografia antiga denominou os primeiros filósofos oi physikói , "os físicos", tendo sido eles os primeiros a empreender o ousado passo que conduz da crença nas representações míticas à admiração e à curiosidade diante da ordem grandiosa da phýsis e da infinita complexidade dos seus fenômenos. Nascia assim a física (...) “. 
É interessante estressar que na antiguidade esses profissionais já tinham dado uma razoável contribuição ao desenvolvimento das engenharias náutica e militar, à astronomia, à arquitetura e ao comércio. Em conformidade com o já enunciado antes, foi no século VI antes de Cristo, quando do aparecimento da famosa Escola Jônica, que nasceu, de fato, o que se definiria, cientificamente, por física. Apesar deste marco histórico, é importante não se desprezar as contribuições anteriores àquelas do mundo grego, para a ciência moderna. É necessário também lembrarmos que no século II (ou III) antes de Cristo, a cidade de Alexandria era, provavelmente, um dos maiores centros da ciência no mundo antigo. Ali foram decifrados nos conventos ou nos mosteiros os "milagres" que só os físicos, de então, admitiam ser os mesmos meros fenômenos físicos. As técnicas de guerra utilizadas pelos exércitos tinham também alcançado grande desenvolvimento. $\mathrm{O}$ modelo geocêntrico de Ptolomeu foi introduzido àquela época. A hidrostática - experimentada através do processo de bombeamento de água - também surgiu no citado período. A estática das construções, estudada exaustivamente naquele tempo, induziu o aparecimento da engenharia civil. As balanças e outros mecanismos de pesagem e medidas foram também desenvolvidos àquela época. Ressalte-se que o magnetismo veio então a lume, apesar de o filósofo Tales de Mileto (623 - 556 a.C) e alguns cientistas indianos já terem contribuído para o entendimento deste ramo da física.

$\mathrm{Na}$ fase expansionista do Império Romano, o que se constata é que, apesar de sua relevância histórica, não estão bem documentadas as contribuições para os fundamentos da física. Apesar disso, a Igreja, principalmente a católica romana, herdeira da cultura grega, impulsionou os estudos em torno da óptica e 
da astronomia que, desde então, tornaram-se tópicos de grande interesse para a humanidade.

Relembrando o século XVII, outra figura notável que tipifica um físico, àquela época, foi Galileu Galilei. Por mentalidade era um homem que continuava a tradição da ciência matematizada da antiguidade. Mas era, também, um habilidoso construtor de instrumentos. Galilei, um quase mártir da ciência foi, sem dúvida, um dos grandes iniciadores da ciência moderna e da modernidade e, infelizmente, recebeu um dos mais longos vereditos de condenação na história das ciências. Após trezentos e cinquenta e nove anos de seu julgamento, pelo tribunal da Inquisição, é que o Vaticano se dispôs a perdoá-lo da condenação, em 1633, pelo fato de ter apoiado distintas teorias físicas, dentre as quais a do heliocentrismo e por decorrência o movimento da Terra. Galilei (1564 - 1642) além de ser um admirador da obra de Nicolau Copérnico (1473 - 1543), autor do livro De revolutionibus orbium coelestium, publicado em 1543, o qual se tornou um marco da astronomia moderna foi, também, um crítico da chamada física aristotélica discutida há centenas de anos. Galilei é considerado o primeiro físico moderno, e desenvolveu uma nova metodologia científica, ao reconhecer o papel fundamental daqueles que fazem ciência, ou seja, o de descrever os fenômenos naturais e tentarem explicar o porquê dos mesmos. Em suas obras estão descritos o movimento de projéteis, a queda livre, além de esclarecer a independência de movimentos verticais e horizontais e a ênfase no uso da matemática para determinar distâncias dos corpos em movimento. Ele foi um exímio experimentalista, aperfeiçoou o telescópio além de ser o descobridor dos satélites galileanos do planeta Júpiter e das fases do planeta Vênus. A ele é outorgado o ápice da nova descrição do movimento de corpos massivos, sob a 
influência de forças atuantes sobre os mesmos, que caracterizaria a denominada mecânica clássica, a qual foi também objeto de estudos do filósofo René Descartes e outros cientistas a exemplo de Johannes Kepler (1571 - 1630), William Gilbert (1544 - 1603) e de Isaac Newton (1643 - 1727) que, ao desenvolver o cálculo dos fluxons ou cálculo diferencial e integral, independentemente de Gottfried Leibniz, fundamentou a mecânica clássica, fazendo com que mais tarde este ramo da física fosse implementado pelos trabalhos de Joseph Louis de Lagrange $(1736$ - 1813), com a mecânica lagrangeana, e William Rowen Hamilton (1805 - 1865), com a mecânica hamiltoniana, as quais viriam contribuir para o desenvolvimento de novos formalismos na física moderna, a exemplo de: física quântica, física relativística e teorias de campos clássicos e quânticos.

Newton (2010) foi o grande unificador das leis do movimento da mecânica clássica, algumas já conhecidas: a lei da inércia, a lei da ação e reação e a que define a força como função da derivada temporal do momentum linear ou quantidade de movimento. $\mathrm{Na}$ sua obra fundamental Philosophiae Naturalis Principia Mathematica, ele descreveu a universalidade de tais leis, além de fazer a grande síntese do mecanicismo, concluindo a primeira grande unificação na história da física, passo esse já iniciado por Galilei. Assim, o cientista pisano, com sua dessacralização dos céus, e Kepler, com o estudo sobre o movimento dos planetas, culminam com o trabalho de Newton sobre a gravitação universal. Novas contribuições à citada mecânica foram trazidas por Leonhard Euler (1707 - 1783) com a teoria do giroscópio e a hidrodinâmica, e a sua contribuição ao estudo das citadas leis newtonianas para os corpos rígidos, além de escrever a forma "fraca" da segunda lei, que define a força como o produto da massa pela aceleração dos corpos. 
O impacto da mencionada mecânica marcou, profundamente, a história da humanidade, ao se verificar a possibilidade de se resolver inúmeros problemas do mundo físico. Enfim, a doutrina mecanicista atingiria o seu apogeu no século XIX. O mecanicismo é definido como "uma filosofia da natureza, segundo a qual o universo e qualquer fenômeno que nele se produza podem e devem explicar-se de acordo com as leis dos movimentos materiais" (BEAUDE, 1987 p. 59). Apesar da grande eclosão do mecanicismo no século XVII, alguns autores buscam pistas sobre possíveis influências, nesta doutrina, de filósofos atomistas gregos, a exemplo de Leucipo de Mileto (circa 500 a.C - ), de seu discípulo Demócrito de Abdera (circa 460 a.C - ) e Epicuro de Samos (341 - 271 a.C.), e no século I a.C., em Roma, Lucrécio (97 - 55 a.C.), que consagrou o poema De rerum natura à doutrina do atomismo. É sabido que tanto na Antiguidade, bem como na Idade Média, os atomistas foram praticamente ignorados; mesmo assim, no citado século XVII, Galilei e outros filósofos mecanicistas recuperaram muitas ideias dos atomistas, a exemplo de uma "composição atômica da matéria", tese esta que permitia independê-los da física aristotélica e das filosofias naturais do período renascentista. De acordo com Beaude (1987, p 61) “(...) os mecanicistas haviam sido seduzidos por este atomismo antigo que lhes trazia uma cosmologia e uma física muito mais de acordo com as suas próprias perspectivas que a filosofia de Aristóteles".

De qualquer maneira não nos iludamos sobre esta influência dos atomistas sobre os mecanicistas, a exemplo de Descartes (1596 - 1650) que rejeitava o atomismo. Segundo Beaude (1987, p. 62), o que se sabe é que "os mecanicistas do século XVII reclamam a liberdade que se obtém dominando a natureza, os atomistas antigos haviam buscado a que se alcança preservando-se da natureza. $\mathrm{O}$ 
mecanicismo que Gassendi (1592 - 1655) encontrou em Epicuro não tinha por finalidade o conhecimento do mundo, ao passo que o do século XVII está ligado a uma sêde de descoberta. O atomismo grego não concorreu, como o mecanicismo europeu da época clássica, para fundar um progresso das ciências".

É bom lembrarmos que a crença de que todos os problemas da física poderiam ser reduzidos àqueles cujas respostas estavam na mecânica clássica, foi descartada a partir do surgimento de inconsistências entre a mecânica clássica e o eletromagnetismo, o que conduziria, no início do século XX, ao aparecimento de novas teorias: as teorias da relatividade e a física quântica, as quais identificariam a mencionada mecânica como um caso particular.

Antes de lembrarmos a "era da eletricidade" é interessante relembrar que quase dois séculos após o auge do mecanicismo iniciou-se outro importante período no caminhar da física, a denominada "era da termodinâmica", que daria sustentação ao desenvolvimento científico ligado à primeira revolução industrial, cuja base territorial situou-se, principalmente, na Inglaterra. Com isso o Reino Unido (UK) teve a sua primeira e talvez mais importante transformação social e econômica. A partir de então a citada nação consolidou-se como grande potência. Ali surgiram, talvez, os primeiros passos do processo que seria chamado, em nossos dias, de globalização: enunciavam-se, então, alguns princípios de integração entre os povos, mas o que se tem observado é o aprofundamento da velha exploração de países poderosos em relação àqueles ditos emergentes e/ou periféricos (SANTOS, 2000, p 52).

Retornando ao caminho histórico deste ramo da física clássica - a teoria do calor ou termodinâmica (ou energética) 
- é importante relembrar que, já no século XVII, as noções básicas de calor e de temperatura eram discutidas. Galilei, por exemplo, foi um precursor para o termômetro - o termoscópio de ar. Desde as civilizações primitivas, as ocorrências básicas de calor já eram conhecidas. Àquela época já havia certo convencimento que as duas citadas propriedades físicas estavam ligadas aos movimentos de estruturas microscópicas da matéria. Apesar disso, no século XVIII, tornou-se dominante a ideia que o calor era uma substância fluida. Essa crença foi, paulatinamente, descartada a partir de 1840, por James Prescott Joule (1818 1889) e outros físicos. Toda essa discussão culminou com a ideia que o calor é de fato uma forma de energia. A utilização da relação entre calor e energia implicaria no desenvolvimento de máquinas a vapor. Lembremos que um pouco antes, Sadi Carnot (1796 1832) já se preocupava com o grau de eficiência de máquinas térmicas idealizadas. Esta área da física é normalmente discutida por meio de dois aspectos - o lado fenomenológico, o qual descreve os processos através de leis empíricas e, a partir da física estatística, conforme enfatizam Pinho e Andrade (2011, p. 142) se "faz remontar o comportamento do sistema macroscópico às características estatísticas de muitas partículas microscópicas, de que consiste o sistema macroscópico".

As bem conhecidas leis da termodinâmica foram enunciadas por célebres atores históricos. Rudolf Julius Emmanuel Clausius (1822 - 1888) e William Thomson (Lord Kelvin; 1824 - 1907) foram os precursores do enunciado da primeira lei, sobre a conservação da energia. Esses mesmos autores buscaram também enunciar os rudimentos da segunda lei. De início eles descreveram que o calor não "flui" de maneira espontânea de um corpo frio para um corpo quente, o que na atualidade é descrito em 
termos da grandeza 'entropia', a qual em qualquer sistema isolado tende a aumentar com o tempo, até alcançar um valor máximo. A rigor o teorema de conservação da energia foi descoberto, independentemente, por Hermann Ludwig Ferdinand Von Helmholtz (1821 - 1894), Joule, e Julius Robert Mayer (1814 — 1878). Para a Termodinâmica, ele havia sido imaginado por Sadi Carnot, mas somente Joule tornou este princípio expressamente claro.

A noção de temperatura foi associada, de início, à sensação de quente e frio; entretanto, esta é uma grandeza característica do corpo num certo instante, não dependendo, pois, da sensação subjetiva dequenteefrio. Talvezestagrandeza possa ser considerada como a primeira grandeza termodinâmica a ser medida (ibidem, p. 142), mas pensemos na grande síntese ou processo comum a todos os termômetros - "o aparelho entra em equilíbrio térmico com o sistema, cuja temperatura se busca medir, ou seja, quando um corpo mais quente entra em contato com um mais frio, após certo tempo, ambos atingem a mesma temperatura”. A observação do mencionado equilíbrio térmico ensejou ao escocês James Clerk Maxwell (1831 - 1879) enunciar a denominada lei zero da termodinâmica: "Se dois corpos estão em equilíbrio térmico com um terceiro, eles estão em equilíbrio térmico entre si”. Mayer concluiria que calor e trabalho são manifestações da energia, que podem se transformar uma na outra, mas não perder. Em 1842, sintetiza - "uma vez criada, a energia não pode ser aniquilada, mas ela pode apenas mudar de forma”. Pinho e Andrade (2011, p.150) estressam que na "sua forma atual, a primeira lei implica que se pode alterar o estado termodinâmico do sistema através da troca de calor ou da realização de trabalho; a grandeza que traduz o estado é a energia interna e, portanto, uma função de 
estado (conjunto de grandezas termodinâmicas macroscópicas que caracteriza o sistema. No caso de um gás monoatômico, o estado termodinâmico é caracterizado por pressão, temperatura e o volume do mesmo)".

A segunda lei da termodinâmica é também denominada de princípio de aumento da entropia "Este princípio analisa a variação de entropia do universo (sistema mais vizinhança) entre dois estados termodinâmicos, considerando o mesmo termicamente isolado: para um processo reversível, não há variação, enquanto que para um irreversível, ocorre aumento". Pinho e Andrade (2011, p. 155) chamam a atenção para a correspondência entre a primeira lei e um princípio de conservação, bem como entre a segunda Lei e um princípio de evolução. "No caso de processos naturais (irreversíveis) o aumento de entropia traduz a degradação de energia, já que o calor trocado, devido a este aumento, corresponde a um trabalho que poderia ser utilizado se a transformação fosse efetuada reversivelmente". Para o caso da física estatística, a entropia mede o grau de desordem do sistema. Em síntese, seguindo a citada autora, a lei zero enuncia que "Dois corpos em equilíbrio térmico com o terceiro, estão em equilíbrio térmico entre si" - a qual serve de base para o processo de medida de temperatura. A primeira lei - "A energia do universo é constante" - que inclui o calor como uma forma de energia. A segunda lei: "A entropia do universo tende a um máximo"; a qual traduz o caráter irreversível de processos naturais. Por fim, lembremos as dificuldades envolvendo a impossibilidade de se atingir a temperatura do zero absoluto, e a contribuição de Hermann Nernst $(1864$ - 1941) que enunciou o teorema que leva o seu nome: "Na vizinhança do zero absoluto num processo isotérmico todas as reações em um líquido ou sólido ocorrem sem 
variação da entropia (potenciais termodinâmicos de Helmholtz e Gibbs". Além de ter sido criticado devido à sua restrição a processos isotérmicos reversíveis, em 1911, Max Planck (1858 1947) sugeriu ajustes ao citado enunciado, tal que além de sua variação, a própria entropia de toda substância líquida ou sólida, em equilíbrio, é nula. Surge então a denominada terceira lei da termodinâmica: "É impossível reduzir a temperatura do sistema a zero absoluto em um número finito de processos". Esta lei é também conhecida por princípio da inatingibilidade do zero absoluto.

Outros atores históricos contribuíram, substancialmente, para os estudos termodinâmicos. Em 1738, Daniel Bernoulli (1700 - 1782) conjecturou que os gases são constituídos por moléculas em movimento. Apesar de não ter sido bem aceita, essa hipótese foi retomada por Clausius, em 1857 e, em 1860, Maxwell formulou, a partir da mecânica de colisão de moléculas individuais, a sua distribuição das velocidades das moléculas em um gás. Tais contribuições implicaram no avanço da teoria cinética dos gases em equilíbrio. Ludwig Boltzmann (1844 - 1906) (com estudos sobre a física estatística e a significação da entropia), após sérias dificuldades com a sua equação que detalhava a evolução de um gás introduziu a famosa expressão em que a entropia de equilíbrio deve ser proporcional ao logaritmo do número de estados possíveis de um sistema e, com isso, iniciou os estudos da física estatística. A consolidação de tal ramo da física (também chamada de mecânica estatística) deu-se no final do século XIX e início do XX, quando do surgimento da teoria quântica (parte da chamada física estatística quântica), com a contribuição de Planck (1991) na resolução do problema do corpo negro, em que se tornou claro que os métodos estatísticos podiam ser também 
utilizados na análise de distintos sistemas físicos além de gases. Seguindo a síntese de Pinho e Andrade (2011, p. 157), o outro avanço nesta área da física foi a formalização do método dos ensembles, que se tornou fundamental para o estabelecimento da física estatística de equilíbrio. E, por fim, aconteceu o surgimento de novas metodologias para a dinâmica aleatória, que conduziram aos novos estudos em torno da física estatística de não equilíbrio.

Prigogine observou "que um sistema mantido longe do equilíbrio termodinâmico por ação externa pode dar origem a quebras espontâneas de simetria, que se manifestam em nível macroscópico". Ele caracterizou este estado como estrutura dissipativa, enfatizando a importância da dissipação para os fenômenos de não equilíbrio. Com a descoberta, em 1967, das estruturas dissipativas o mencionado detentor do prêmio Nobel de Química, de 1977, introduziu a noção de complexidade, da ordem que pode nascer do caos (PINHO e ANDRADE (2011, p. 179).

No século XIX surgiria, de novo, outra teoria unificadora na física, relacionada à denominada "era da eletricidade", a qual desempenharia papel importante nos avanços tecnológicos que surgiram na chamada segunda revolução industrial, cuja maior visibilidade foi alcançada na Alemanha.

Apesar de gregos, indianos e outros povos já conhecerem desde a antiguidade as forças magnética e elétrica, estas ficaram bem caracterizadas por cientistas como Petrus Peregrinus de Maricourt (1220 - 1270) (estudos sobre polos magnéticos em agulhas magnetizadas), William Gilbert (no sec. XVI), Benjamin Franklin (1706 - 1790) (com trabalhos sobre o armazenamento de 
cargas elétricas). Outros, no século XVIII, também apresentaram contribuições importantes: Charles Augustin de Coulomb, Siméon-Denis Poisson, Pierre-Simon Laplace e Karl Friedrich Gauss, que introduziram os recursos da física-matemática a fim de interpretar os resultados experimentais, a partir de novas leis. Outros personagens marcantes: Hans Christian Oersted, André Marie Ampère e Michael Faraday, que introduziu o conceito de campo e influiu fortemente na matematização de fenômenos elétricos e magnéticos. De acordo com Faraday, o campo estáligado à distorção no espaço causada pelas presenças de cargas elétricas e magnéticas, com a ação de tal entidade ocorrendo sob a forma de "linhas de força". Faraday foi um grande experimentalista e construiu diferentes dispositivos (motor elétrico, transformador, dínamos etc.).

Maxwell realizou a tarefa de unificar os resultados conseguidos por Gauss, Ampère, Neumann, Lenz e Faraday, edificando a teoria eletromagnética, a partir de quatro equações que sintetizam as leis básicas do eletromagnetismo clássico (lei da Gauss da eletrostática, lei de Gauss do magnetismo, lei de Faraday-LenzNeumann e a lei de Ampère-Maxwell da eletrodinâmica clássica). A partir de uma ansatz Maxwell generalizou a lei ordinária de Ampère, e definiu a corrente de deslocamento como fonte do campo magnético, dependente do tempo. Ele mostrou que a óptica é parte do eletromagnetismo e a velocidade da luz depende apenas de parâmetros eletromagnéticos. Heinrich Rudolf Hertz, em 1888, conseguiu experimentalmente detectar as ondas eletromagnéticas, previstas no formalismo maxwelliano, e com esse evento contribuiu para o grande avanço tecnológico nos últimos séculos. 


\section{A FÍSICA NA CONTEMPORANEIDADE}

Afirmamos, anteriormente, que não estaríamos preocupados com a rígida cronologia e, portanto, discutiremos os caminhos da física a partir do século XX, através de três vertentes: a física dos quanta (ou física quântica ou mecânica quântica), a física relativística (a teoria da relatividade restrita ou especial e a teoria da relatividade geral ou generalizada ou teoria da gravitação do Einstein) e a física não linear, as quais foram desenvolvidas, independentemente. Graças aos seus fundamentos e formulações podemos caracterizar outras teorias que se interligam a esses distintos ramos da física na contemporaneidade, a exemplo da eletrodinâmica e da cromodinâmica quânticas.

Nas últimas décadas, vários pesquisadores tiveram contato com os fenômenos não lineares, que hoje se apresentam em distintas áreas da ciência e, em particular, na física moderna e contemporânea. Na década de 1970, a não linearidade começou a ser discutida em vários sistemas dinâmicos, principalmente, na física da matéria condensada, em que, por exemplo, os denominados sistemas incomensuráveis apresentam estruturas incomensuráveis e comensuráveis, quando atingem certas temperaturas críticas em transições de fase. Exemplos de tais estruturas surgem em vários materiais ferroelétricos, ferromagnetos, cristais líquidos e sistemas que se apresentam com ondas de densidade de carga. $\mathrm{O}$ mais interessante é que as citadas estruturas incomensuráveis se apresentam, formalmente, conectadas com as denominadas ondas solitárias. Várias dessas ondas, chamadas sólitons, caracterizam-se por serem não lineares e não dispersivas. Ribeiro Filho e Vasconcelos (2006, p. 397) ao discutirem a não linearidade em física, enfatizaram alguns 
aspectos básicos sobre o problema não linear. As questões que envolvem os sistemas não lineares, em distintas áreas da física e de outras ciências, têm despertado um grande interesse nos tempos modernos. Para isso, o papel da matemática na elucidação de problemas que envolvem os mencionados sistemas tem sido marcante e chama a atenção para uma questão que tem causado perplexidade e induzido discussões extremadas, ou seja, a não linearidade versus física quântica.

A utilização da matemática como possível "linguagem" que expressa as leis da natureza surgiu, com grande ênfase, no século XVII, com Galilei. Apesar do sucesso em alcançar tal objetivo, alguns autores têm chamado a atenção sobre o papel da citada matematização. Giles (1984, p. 31) esclarece que nesta linha de raciocínio "temos uma representação correta da natureza quando o modelo expresso pela linguagem simbólica da matemática se mostra de acordo com os fatos públicos comprovados pela experimentação". Com referência a esse período da história, Paty (1995, p. 65) lembra que àquela época, a matemática "era concebida como um conhecimento que permitia uma leitura direta da natureza, da qual, precisamente, era a língua".

É importante salientar que Galilei se reportava, basicamente, à geometria como sendo a mencionada "língua". Para o físico e filósofo italiano, o que interessava "era apenas as ordens de grandeza" envolvidas no acordo numérico com os fatos experimentais. De acordo com Paty, com o avanço da físicamatemática surgiria a substituição dessa "tradução matemática" da natureza por uma "elaboração explícita de conceitos físicos pensados matematicamente; sendo a matematização concebida como inerente aos conceitos, constitutiva desses, que serve para construí-los". 
Apesar de ser bem sucedida, a ligação entre as duas ciências (física e matemática) não tem sido alvo de referências suaves, por parte de alguns notórios atores históricos. Para Descartes (1641, 1647) a matemática "só trata de coisas muito simples e muito gerais, sem se preocupar muito se elas estão ou não na natureza". Poincaré (1854 - 1912) diria "o que ela (matemática) ganhou em rigor, perdeu em objetividade. Foi distanciando-se da realidade que ela adquiriu essa pureza perfeita".

Apesar de tais asserções é interessante ratificarmos que há diferentes maneiras de se modelar, matematicamente, os distintos sistemas físicos, desde o modelo fenomenológico interligado, fortemente, a dados empíricos, até o estágio mais sofisticado em que se formula a axiomatização da teoria. Estas formas de modelagem visam enfatizar o rigor no raciocínio matemático aplicado à física. Infelizmente, levando em conta as distintas correntes do pensamento matemático (logicismo, intuicionismo e formalismo), o mencionado rigor não se livra, com facilidade, de uma clara desconfiança (RIBEIRO FILHO e VASCONCELOS (2006, p. 399).

Prosseguimos chamando a atenção para alguns aspectos matemáticos ligados aos sistemas não lineares, que se apresentam na natureza, em particular aqueles estudados nas últimas décadas por matemáticos e físicos. Esses sistemas, em vista de suas peculiaridades intrínsecas, têm despertado um misto de curiosidade e estranheza. Essas características conduziram, durante um certo período, à crença sobre a impossibilidade prática em se efetivar a busca em torno de um melhor entendimento sobre a física subjacente aos mencionados sistemas. Do ponto de vista histórico é interessante lembrar o papel desempenhado pelo método matemático de perturbações, aplicado a esses sistemas. 
Durante décadas ele foi o principal aparato analítico disponível, a físicos e matemáticos, com o fito de se estudar as diferentes propriedades físicas e matemáticas nos citados sistemas.

Apesar de sua respeitabilidade, o método perturbativo apresenta limitações e dificuldades, o que levou distintos cientistas a apresentarem resultados nem sempre muito esclarecedores para os fenômenos estudados. É interessante relembrar as dificuldades enfrentadas por Delaunay $(1816$ - 1872), no trabalho sobre a trajetória da Lua, desenvolvido em 1842. O citado autor, ao usar uma aproximação perturbativa de sétima ordem, para equacionar o trajeto lunar, o obteve através de uma equação final cuja expressão necessitou de cento e setenta páginas impressas, para a sua completa leitura. Hagedorn (1984) ao lembrar o trabalho do citado físico e astrônomo francês afirmou: "Graças a Deus aqueles são tempos passados. Hoje, os métodos analíticos de aproximação têm um significado diferente daquele tempo, anterior aos computadores eletrônicos". Esta frase indica as expectativas que envolviam alguns pesquisadores, em torno da física não linear, até o final do século XIX. Somente com os trabalhos de Poincaré e outros, em mecânica neo-qualitativa (ou mecânica clássica moderna) e na matemática não linear, é que uma nova onda de trabalhos seminais indicaria e confirmaria a respeitabilidade dessa milenar área da física.

Nicolis (1989) ao se posicionar sobre a questão da linearidade afirma que: "indubitavelmente, por sua atratividade cultural, a ideia - que um sistema natural submetido a condições externas bem definidas seguirá um único caminho curvo e que uma mudança suave nessas condições induzirá, provavelmente, uma leve mudança na resposta do sistema - Esta ideia, com os seus corolários de reprodutibilidade e previsibilidade ilimitada 
e, portanto, de definitiva simplicidade, tem por muito tempo dominado o nosso pensamento e tem conduzido, gradualmente, à imagem de um mundo linear, aquele em que os efeitos observados estão ligados a causas subjacentes por um conjunto de leis reduzido para todos propósitos práticos a uma simples proporcionalidade".

Com o surgimento de desvios qualitativos no regime de proporcionalidade e, por conseguinte, o aparecimento da não linearidade, o mencionado autor enfatiza que: "a diferença notável entre as leis dinâmicas e não lineares é se a propriedade (ou princípio) da sobreposição linear é válida ou não. Em um sistema linear o efeito definitivo da ação combinada de duas diferentes causas é meramente a sobreposição dos efeitos de cada causa tomados individualmente. Mas, em um sistema não linear, ao somar-se duas ações elementares, uma à outra, pode-se induzir novos efeitos dramáticos refletindo o início de cooperatividade entre os elementos constituintes. Isto origina estruturas inesperadas e eventos cujas propriedades podem ser bastante diferentes daquelas das leis elementares subjacentes, numa forma de transições abruptas, numa multiplicidade de estados, na formação de padrões, ou em uma marcante, irregular e imprevisível evolução no espaço e tempo conhecida como caos determinístico. A ciência não linear é, portanto, a ciência da evolução e complexidade".

A dinâmica caótica, iniciada a partir de trabalhos de Poincaré, recebeu grandes contribuições de célebres matemáticos: Birkhoff, nos anos 1920; Mary L. Cartwright e J. E. Littlewood, nos anos 1940; e Smale, Kolmogorov, Arnold, Moser e outros na década de 1960. Retornando às ondas solitárias, que são não lineares, a história de sua descoberta é bem interessante. Em 1834, John 
Scott Russell, engenheiro e arquiteto naval, de origem escocesa, observou pela primeira vez o fenômeno das ondas solitárias. Ele ao seguir o movimento de um pequeno barco num canal estreito, na cidade de Edimburgo, viu o mesmo parar abruptamente, ao atingir um escolho. Com o impacto, uma quantidade de água começou a se deslocar mantendo, por um longo tempo, a sua forma original. Russell impressionou-se e denominou tal fenômeno de onda solitária e, apesar de muito esforço, não conseguiu determinar a equação diferencial parcial (EDP) a ele associado. Somente, em 1895, após a morte de Russell, os holandeses Korteweg e o seu aluno de doutorado, De Vries, obtiveram a chamada EDP de KdV, para a propagação de ondas em uma direção na superfície de um canal raso. Por muitos anos essas ondas permaneceram quase ignoradas e, em 1955, Fermi, Pasta e Ulam (1965, p. 978) conseguiram uma relação entre a EDP de KdV e o comportamento bizarro de sistemas, originalmente lineares, nos quais foram introduzidas perturbações não lineares. Ao observarem que soluções tipo ondas solitárias da equação de KdV não se dispersavam e mantinham as características iniciais após colidirem, os físicos Zabusky e Kruskal, em 1965, chamaram tais ondas de sólitons (solit, de solitária; on : palavra grega para "partícula"), o que sugere que essas ondas têm um comportamento corpuscular. Em 1967, ainda inspirados no célebre problema de Fermi, Pasta e Ulam; Gardner, Green, Kruskal e Miura (1967) utilizaram o método do espalhamento inverso a fim de obter soluções da EDP de KdV.

No centro da física não linear está o conhecido problema do pêndulo matemático o qual, para muitos, é o sistema físico responsável pela gênese da teoria dos sistemas dinâmicos. Galilei, em 1581, estava no interior da Catedral de Pisa, e teve a ideia de 
estimar o período de oscilação de um candelabro que oscilava, contando o seu próprio batimento cardíaco (GITTERMAN, 2008, p. v). Ele viria concluir que o período das pequenas oscilações não dependia nem da amplitude do movimento, nem da massa " $m$ " do objeto. A dependência era apenas do comprimento efetivo "L" do barbante (a distância entre o ponto de sustentação do barbante e o centro de massa do objeto). De fato, o comportamento de um pêndulo simples, num campo gravitacional, submetido a um amortecimento linear e uma força externa $\mathrm{F}(\mathrm{t})$ pode ser descrito em termos de " $\Theta$ " que é o deslocamento angular do pêndulo

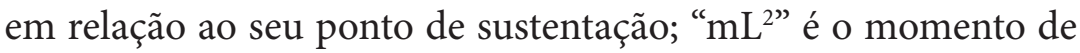
inércia; "b" é a constante de amortecimento e "mgL sen $\Theta$ " é o torque restaurador devido à aceleração da gravidade "g". Este sistema pode representar diferentes sistemas físicos, e no caso em que " $b=0$ " e " $F=0$ ", a equação correspondente reduz-se à equação conhecida por equação de seno-Gordon, ou equação do pêndulo matemático, cuja solução determina o surgimento de sólitons ou ondas solitárias, tão importantes em distintos ramos da física: cosmologia, física de partículas, física da matéria condensada, óptica quântica, óptica não linear e outros.

A outra vertente no caminhar da física, no século XX, surgiu a partir da contribuição de Einstein, a partir de seu ano miraculoso (1905), em que introduziu a teoria da relatividade restrita (ou especial). Em 1915, ele criou a teoria da relatividade geral ou generalizada, também conhecida por teoria da gravitação de Einstein . Não nos estenderemos muito nestes tópicos, apesar de sua grande importância histórica e filosófica. Em conjunto com a física quântica, elas permanecem incitando as mentes dos físicos, matemáticos e filósofos, na busca de respostas para problemas na contemporaneidade. Entre esses, por exemplo, aquele ligado 
à grande unificação das interações (gravitacional, eletrofraca e a nuclear forte) na natureza.

Em súmula, dentre as grandes novidades surgidas com a teoria da relatividade restrita, o espaço e o tempo deram lugar a um novo ente denominado por Poincaré (2008) de "espaçotempo", o que daria lugar a novas propriedades não encontradas no mundo newtoniano: a dependência da massa com a velocidade, a relação da energia com a massa relativística, o caráter relativo, ou de dependência, nos referenciais inerciais, das medidas de comprimentos e intervalos de tempo, e por fim o caráter não absoluto do princípio da simultaneidade de eventos. Enfim, esses novos aspectos trazidos pela nova teoria einsteiniana, apesar do grande sucesso alcançado, tornaram-se alvos de discordâncias entre filósofos, a exemplo do francês Bergson (1859 - 1941), que discordou da noção de tempo de Einstein. Com referência aos desentendimentos entre os dois nobelistas, Prigogine (2002, p. 76) diria: "Nem Bergson entendeu Einstein e nem Einstein entendeu Bergson".

A primeira teoria relativística, citada acima, parte de dois axiomas, um deles postula a constância da velocidade da luz "c" no espaço vazio, e o outro a não existência de referenciais inerciais privilegiados. Apesar de receber críticas, Einstein teve o apoio de outros cientistas e filósofos. Bachelard (1884 - 1962), pensador francês, foi um entusiasta das teorias relativísticas e da teoria quântica e, em diversas obras, discutiu, filosoficamente sobre o novo espírito científico. Ele declarou que "com a ciência einsteiniana começou uma revolução sistemática das noções de base. É no próprio detalhe das noções que se estabelece um relativismo do racional e do empírico" (BACHELARD, 1984). Em 1915, Einstein apresentou a sua teoria da gravitação, na 
qual generalizou a sua teoria de 1905, ao considerar a necessária contribuição da gravitação e a presença de referenciais não inerciais. A sua nova teoria conseguiu resolver problemas para os quais a teoria da gravitação de Newton não pôde dar resposta acurada.

Para Bertrand Russell a contribuição da teoria da relatividade geral era evidente; entretanto, segundo ele, do ponto de vista filosófico, a sua importância era incomensurável. O certo é que após o advento desta teoria, objetos como buracos negros, quasares, teorias cosmológicas como a do Big-Bang, conjecturas sobre a expansão do universo, descoberta de novos planetas, o estudo das galáxias, enriqueceram a astronomia e astrofísica modernas.

O impacto das ideias de Einstein sobre a física teórica é imensurável. Na sua primeira teoria relativística foi o matemático Minkowsky quem primeiro utilizou o princípio da invariância de Lorentz, que envolve as equações de Maxwell do eletromagnetismo clássico, de tal maneira que no mundo einsteiniano as equações de campo são covariantes com respeito à citada invariância. De acordo com o nobelista Yang, o criador das teorias da relatividade impressionou-se com as poderosas consequências físicas dos princípios de simetria e trabalhou para alargar o escopo da invariância de Lorentz. "Esta ideia de uma invariância de coordenadas mais geral conduziu, junto com o princípio de equivalência, à teoria da relatividade geral". Para Yang, o físico Einstein foi o iniciador do princípio que symmetry dictates interactions, o qual tem desempenhado um papel essencial na origem de várias teorias de campo, que não discutiremos neste trabalho. 
Apesar de ser considerada uma das grandes teorias da história da física, a teoria da relatividade geral tem sido submetida a distintos testes experimentais, com sucesso. Entretanto, alguns autores a criticam, enumerando o que eles rotulam de "insuficiências" da mencionada teoria einsteiniana. Para Sommerfeld (1952), o "feito positivo da teoria da relatividade não é tanto a completa relativização do espaço e do tempo, mas a prova de que as leis da natureza são independentes da escolha dos sistemas de referência, isto é, que os fenômenos são invariantes para quaisquer observadores". Para ele seria melhor chamá-la "teoria da invariância" em vez de "teoria da relatividade", que foi o nome outorgado por Max Planck, em 1906, enquanto Einstein preferia a primeira denominação.

Finalmente, destacaremos o último estágio desta caminhada em torno da física, sublinhando, com brevidade, alguns dos aspectos essenciais da chamada física dos quanta ou física quântica ou mecânica quântica. Este ramo da física tem como marco histórico o dia 14 de dezembro de 1900, quando Max Karl Ernst Planck (1858 - 1947), em uma conferência na Sociedade de Física de Berlim, anunciou a sua solução para o problema da radiação do corpo negro (Blackbody radiation). Esse sistema (corpo negro), em linhas gerais, caracteriza um corpo aquecido que, em tese, seria um absorvedor quase perfeito e cuja representação pictórica seria aquela de uma cavidade com um minúsculo orifício, a fim de evitar, ao máximo, a saída de radiação. $\mathrm{O}$ mencionado problema intrigou a comunidade dos físicos no final do século XIX e surgiu quando da busca em torno da produção de aço de melhor qualidade, o que ocasionou, segundo Osada (1972, p. 35), a procura do controle rigoroso da temperatura de altos fornos. Àquela época, o mundo estava 
envolvido na chamada segunda revolução industrial, e algumas experiências, em torno da distribuição espectral da radiação do corpo negro, desenvolvidas por Rubens (1865 - 1922), Kurbaum (1857 - 1927) e outros apresentavam um resultado caracterizado por um conjunto de curvas experimentais, em que para distintas temperaturas $(1600 \mathrm{~K}, 1800 \mathrm{~K}, 2000 \mathrm{~K}$ etc.), havia sempre uma região de máximo de intensidade energética entre duas regiões (de pequenos e de grandes comprimentos de onda) em que tal intensidade tendia a zero, ou seja, próximo à região ultravioleta do espectro ou longe da mesma a mencionada intensidade ou emitância espectral, para o corpo negro, diminua intensamente.

Para interpretar tais resultados experimentais, alguns modelos teóricos foram desenvolvidos, sob a égide da física clássica (mecânica clássica, termodinâmica e eletromagnetismo de Maxwell-Lorentz). Infelizmente, para os seus autores: Lord Rayleigh, James Jeans, Wien, Paschen, Stefan e Boltzmann, os resultados deduzidos teoricamente não eram compatíveis, inteiramente, com as citadas curvas experimentais. Foi nesse período que Planck introduziu a sua famosa hipótese ou ansatz quântica, em que partindo do pressuposto que um corpo negro poderia ser pensado como um sistema formado por um conjunto de osciladores, ele se viu na contingência de ignorar um dos pilares da física clássica, o da continuidade da energia do sistema, e conjecturar que a radiação do corpo negro deveria ser emitida em minúsculos pacotes (ou quanta) energéticos, em qualquer intervalo de tempo considerado. Ou seja, $\mathrm{E}=\mathrm{nhf}$, em que $\mathrm{E}$ representa a energia, $\mathrm{f}$ é a freqüência, $\mathrm{n}$ é um número inteiro $\mathrm{e} h$ é a constante de Planck, cujo valor medido é dado por $\mathrm{h}=6,62 \mathrm{x}$ $10^{-34} \mathrm{~J} . \mathrm{s}$. 
No período de 1900 a 1923 foi denominado de "velha mecânica quântica", pois ainda persistiam alguns resquícios da física clássica na explicação dos novos fenômenos, a exemplo do efeito fotoelétrico e do problema do átomo de hidrogênio. Em 1905, Einstein conseguiu interpretar o problema da interação entre a radiação luminosa e uma superfície metálica, utilizando a ansatz quântica e com isso escreveu a equação fotoelétrica que lhe proporcionou o prêmio Nobel. A partir desse trabalho ele intuiu que a luz era formada por átomos ou quanta luminosos, os quais, em 1926, seriam intitulados fótons, pelo químico inglês G. Lewis. Essa interpretação einsteiniana indicaria o caráter dual da luz. Anos depois, Niels Bohr, vindo de Copenhague, conseguiu detectar dificuldades no modelo solar, de Rutherford, para o átomo de hidrogênio. Observando a eletrodinâmica de MaxwellLarmor, ele usou a ansatz quântica e introduziu dois axiomas com os quais conseguiu edificar o agora conhecido modelo de BohrRutherford, em que as órbitas bohrianas, para os elétrons, são discretas e há a relação de energia de Planck para o movimento de elétrons entre as órbitas.

A partir de 1923, Louis de Broglie, aristocrata francês, em sua tese de doutoramento, conjecturou que "o elétron é uma onda". Com essa asserção, a exemplo do que aconteceu com a interpretação fotônica de Einstein, de 1905, de Broglie assumiria a natureza dual para o elétron e, por conseguinte, para a matéria. As experiências desenvolvidas pelos americanos Clinton Davisson e L. Germer, os ingleses George Thomson e Alexander Reid e o russo P. Tartakowsky conseguiram demonstrar o caráter ondulatório do elétron, através de experimentos de difração de elétrons em cristais e, por consequência, formalizaram-se as ondas de matéria. 
Pois bem, para definir esta nova mecânica surgiram, inicialmente, entre 1925 e 1927, três formalismos matemáticos. O primeiro descoberto por Werner Heisenberg, denominado de mecânica das matrizes, estuda os fenômenos quânticos utilizando o cálculo matricial a partir do axioma em que o operador que representa a posição $(\mathbf{x})$ da partícula e aquele que representa o momentum linear da mesma partícula, na mesma direção, $\left(\mathbf{p}_{\mathbf{x}}\right)$, são grandezas ditas incompatíveis, ou seja, não podem ser medidas simultaneamente. Erwin Schroedinger introduziu a mecânica ondulatória, chamada de mecânica dos operadores por Bachelard, que tem por base as ondas de matéria de de Broglie. Em 1927 surgiu a teoria das transformações ou das representações ou álgebra quântica, segundo o seu autor, Paul Maurice Adrien Dirac, a qual se constituiu numa poderosa abordagem algébrica da física dos quanta. Este último formalismo foi também desenvolvido, independentemente, por Pascoal Jordan (1902 - 1980).

Dos três mencionados formalismos, que reproduzem os mesmos resultados experimentais, o mais difundido é a mecânica ondulatória. Schroedinger introduziu um objeto matemático, a função de onda, $\Psi$, o qual viria representar o estado de um sistema quântico, e que, de acordo com a interpretação de Max Born é também denominada amplitude de probabilidade, pois o módulo ao quadrado da função de onda, $\|\Psi\|^{2}$, representa a densidade de probabilidade de se encontrar a partícula em uma certa região do espaço. De acordo com Isham (1995, p. 9), a mecânica dos quanta apresenta quatro características básicas: a questão probabilística que impõe um determinismo estatístico; a redução do pacote de onda, que é ligada à questão da medida quântica, o problema da incerteza e o emaranhamento quântico. Estas questões surgiram com as discussões iniciais, em torno 
dos fundamentos da teoria quântica, estabelecidas em centros científicos de Paris, Cambridge, Göttingen e, principalmente, em Copenhague, na Dinamarca, onde Niels Bohr, ao retornar de Manchester (UK) e com o prestígio adquirido pelos seus trabalhos em torno do problema atômico, fundou o Instituto de Física Teórica de Copenhague (que hoje tem o seu nome), em que, reunindo vários cientistas (físicos, químicos, matemáticos) estabeleceu a chamada escola ou doutrina de Copenhague, que incorpora a chamada interpretação ortodoxa da teoria quântica.

A mencionada interpretação tem por base o famoso princípio ou tese da complementaridade (ligado ao problema da dualidade onda-corpúsculo na radiação e na matéria), e os princípios da correspondência (que indica o problema da ligação quânticoclássico, a partir de $\mathrm{h} \rightarrow 0$, em que h é a constante de Planck), da sobreposição (ligado ao problema da linearidade e medida quânticas) e, finalmente, o da incerteza ou indeterminação de Heisenberg. A partir destes princípios, a teoria pôde ser axiomatizada como uma teoria da mecânica abstrata, a partir de dois conceitos primitivos (o estado e as observáveis quânticas representadas por operadores lineares hermitianos); uma relação cinemática (que representa a medição quântica) e uma relação dinâmica (representada pela evolução da função de onda, no espaço e no tempo, dada pela EDP de Schroedinger).

Apesar de ser considerada uma teoria poderosa e de grande sucesso, a teoria dos quanta não é considerada uma unanimidade. Bunge (1973) afirmou que apesar de seu sucesso ela "tem a filosofia mais fraca". Trainor e Wise (1981, p. 123 ) afirmam que tal teoria, apesar de ser uma teoria pragmática, que tem gerado grandes avanços tecnológicos nos últimos séculos, "é também uma criação artística que incorpora uma bela e sofisticada 
estrutura conceitual, fundamentada numa elegante formulação matemática e apresenta, além disto, uma teoria da medida bastante elaborada”.

Toda esta discussão é uma herança das discussões iniciadas no V Congresso de Solvay, realizado em Bruxelas, Bélgica, no período de 24 a 29 de outubro de 1927, em que o centro era o problema da realidade quântica. A partir daquele encontro de cientistas estabeleceu-se o mais célebre debate científico do século passado, em que os principais antagonistas eram Bohr e seguidores, em defesa da doutrina copenhaguense, apresentando o postulado quântico, em que a nova teoria renunciava à descrição causal dos fenômenos atômicos no espaço e no tempo, e, do outro lado, Einstein e outros físicos, que não concordavam com a afirmação dos bohrianos de que a existência dos quanta era uma ideia primeira. Em síntese, a culminância desse debate estabeleceu-se em 1935, quando Einstein, Podolski e Rosen escreveram o célebre artigo, denominado de "paradoxo de EPR" que mereceu resposta imediata por parte de Bohr.

O fato é que o experimento de pensamento EPR conseguiu pôr às claras "as peculiaridades profundas da descrição quântica de um sistema físico extenso no espaço" (DAVIES e BROWN, 1991, p. 26), a partir de uma possível "violação" do princípio da incerteza de Heisenberg, um dos pilares da doutrina de Copenhague. Bohr rejeitou o raciocínio de Einstein. Nessa querela o que faltava era uma verificação experimental prática a qual "pudesse discriminar as perspectivas de Einstein das de Bohr, pondo em evidência a cooperação ou ação fantasmagórica à distância reclamada por Einstein. Tudo isso teve de esperar dezenas de anos para novos resultados" (ibidem, p. 61). 
A interpretação de Copenhague defende que em certo sentido, "o átomo não medido não é real: seus atributos são criados ou realizados no ato de medição". Os critérios de "realidade" desta escola influenciaram de forma profunda o mundo dos físicos; entretanto, a partir dos anos 1950 e, principalmente, após os trabalhos do físico John Stewart Bell (1964), o tema da "realidade quântica" retomou o seu papel de destaque, entre os físicos, epistemólogos e historiadores das ciências. O causador da renovação do debate da "realidade" é o hoje célebre teorema de Bell, que tem sido considerado um dos mais fundamentais resultados da ciência (RIBEIRO FILHO, 2011, p. 354).

O teorema de Bell não é uma mera conjectura ou suposição, tem algumas demonstrações matemáticas, o que implica afirmarse que, se de início são aceitas algumas poucas hipóteses, a conclusão certamente aparecerá. O que está subjacente a essa discussão é que Bell não trouxe nem meramente admitiu, ou sugeriu, algo em torno da realidade, e sim, provou, dentro de critérios matemáticos, a asserção que "a realidade é não local". Para Herbert (1983), este teorema trouxe uma contribuição imensurável para ajudar a esclarecer a questão ou problema da realidade quântica. No atual debate em torno deste tema, ébastante difundido que nenhum modelo local poderá explicar os fatos do mundo quântico. Os efeitos deste teorema ainda continuam deixando perplexos os distintos círculos de cientistas. Para Davies e Brown (1991, p. 29), o citado teorema abre o "caminho para uma verificação experimental dos fundamentos da mecânica quântica e uma escolha definitiva entre a ideia de Einstein de um mundo localmente real e a concepção de Bohr de um mundo um tanto ou quanto fantasmagórico, repleto de conspirações subatômicas". De acordo com o paradoxo de EPR, a teoria quântica, apesar de seu 
sucesso é uma teoria incompleta. "É possível pensar em alguma teoria ainda não descoberta, da natureza, para a qual a mecânica quântica agisse como uma espécie de aproximação estatística. Uma teoria mais completa contém variáveis que correspondem a todos os elementos "de realidade". Deve existir algum mecanismo que age sobre essas variáveis para originar os efeitos observados de observáveis quânticas não comutativas, ou seja, o princípio de incerteza de Heisenberg. Esta é a teoria chamada de variáveis escondidas (hidden variables).

Em 1964, Bell mostrou que as predições da teoria quântica, no experimento de pensamento de EPR, são levemente distintas daquelas de uma larga classe de teorias de variáveis escondidas. Grosso modo, a fisica quântica prediz correlações estatísticas mais fortes entre os resultados de medidas realizados sobre distintos eixos do que teorias de variáveis escondidas. Tais diferenças são expressadas usando desigualdades conhecidas por "desigualdades de Bell”, as quais são em princípio detectáveis. A experiência de Aspect (1982), para verificar essas desigualdades, foi a que obteve maior sucesso.

A questão posta pelos protagonistas do EPR, "pode a mecânica quântica ser considerada uma teoria completa?", apesar de ter sido quase ignorada por muitos físicos, influenciou uma parcela menor de pesquisadores com tal intensidade que, segundo Cunha $(2005,2007)$, os anos 1980 trouxeram para o laboratório a questão da "não localidade" - viva ainda hoje, pois cada experimento de violação da desigualdade de Bell é seguido por alguns contraargumentos sobre situações não completamente controladas e que podem afetar os resultados. De acordo com este autor, nos últimos anos o debate amadureceu, sensivelmente, tal que "ao invés de se questionar se a teoria possui não-localidade, se isso 
é desejável sob diversos pontos de vista (...) a questão tornouse: será que esta não-localidade pode ser útil? Será que alguma tarefa pode ser melhor realizada usando as características da mecânica quântica do que com os métodos clássicos? Assim, o emaranhamento, termo criado por Schroedinger para descrever o estado das partículas de Einstein, Podolski e Rosen, passava de vilão para mocinho".

A mecânica quântica, uma das mais bem sucedidas áreas da física, desde o século passado passou a necessitar de uma computação sofisticada, a fim de descrever analítica e numericamente os resultados experimentais. A busca incessante dos físicos e matemáticos por essa maquinaria de cálculos influenciou o desenvolvimento da matemática pura e aplicada e, por consequência, a área da informação, de tal maneira que esses avanços implicaram na aplicação da teoria quântica a problemas de computação científica, o que seria viabilizado pela atual teoria quântica da informação. Surgiu assim este caminho, ainda em andamento, que tem conduzido às aplicações da teoria quântica ao tratamento da informação.

A esperança de ter-se em futuro próximo a possibilidade de estarmos cada vez mais próximos de escalas atômicas, para a armazenagem da informação, nos leva a crer que a citada teoria quântica da informação é um campo promissor e necessário para a futura e esperada tecnologia ligada à computação quântica.

Nestes tempos recentes, muitos físicos têm se dedicado ao estudo de fenômenos novos como a teleportação, o qual é o processo que estabelece, previamente, correlações quânticas entre duas partes, próximas ou não, em que "o estado quântico de uma nova partícula pode ser transferido de um lugar para outro" (CUNHA, 2007, p. 33). Essas correlações caracterizam 
o denominado emaranhamento que é consumido na execução do processo de teleportar, o qual é fundamental na computação quântica. Por enquanto, as notícias sobre os avanços rumo a essas pesquisas computacionais, consideram algumas aplicações de criptografia quântica. No fundo o que se busca na computação quântica, usando a óptica quântica, é processar, transmitir e armazenar informações utilizando correlações. Apesar de todo o empenho dos pesquisadores, a construção dos mencionados computadores quânticos é ainda uma tarefa que apresenta muitas dificuldades.

Com todos esses eventos que têm sacudido a mecânica quântica (emaranhamento, descoerência, teletransporte, criptografia e computação quânticas, etc), o que se sabe, atualmente, é que a mecânica quântica "pode sim ser utilizada de maneira vantajosa em diversas tarefas de processamento da informação. O emaranhamento é personagem central nesta teoria, mas como bom personagem, ainda guarda mistérios. Não existe ainda uma teoria completa sobre o emaranhamento!" (CUNHA , 2005, p. 52).

\section{CONCLUSÕES}

Neste trabalho tentamos discutir alguns dos principais ramos ou caminhos da física, desde a antiguidade, chamando a atenção para a persistência dos físicos na busca de respostas para o esclarecimento de distintos fenômenos naturais. Em particular lembramos que em julho de 2012 houve o anúncio da descoberta da partícula bóson de Higgs, conjecturada nos anos 1960, a qual confirma a unificação das forças nuclear fraca e eletromagnética 
(interação eletrofraca). Relembramos distintas etapas, a exemplo do desenvolvimento das mecânicas, eletromagnetismo, nãolinearidade, relatividades e a física dos quanta.

Encerramos tal discussão enfatizando alguns aspectos da ainda recente teoria quântica da informação e o caminho que possibilitará a busca do computador quântico. Este tema recebeu grande ênfase a partir da contribuição do nobelista Richard Feynman ao inferir que nenhum sistema clássico pode simular um sistema quântico eficientemente. De acordo com este autor, somente um sistema quântico pode, com eficiência, simular outro sistema quântico. Assim, a exemplo de seu pioneirismo ao introduzir os aspectos básicos da nanociência/nanotecnologia, o mencionado cientista foi também precursor ao afirmar que somente os computadores quânticos teriam a possibilidade de modelar os sistemas descritos pela teoria dos quanta.

Enfim, para finalizar esta breve explanação, sobre um possível roteiro em torno do caminhar da Física, lembramos outro enunciado do nobelista Prigogine (2002):

"Gostaria de insistir sobre o fato de que estamos somente no início da ciência. As leis fundamentais de Newton, de Einstein e de Schroedinger ainda descrevem apenas coisas muito simples, reversíveis. Não só estamos no início da neurofisiologia ou de outras ciências limítrofes, como também em física, e mesmo em matemática, compreendemos muito pouca coisa!“.

NOTA

'Instituto de Física da UFBA - PPGEFHC. ribfilho@ufba.br - ribfilho@uol. com.br 


\section{REFERÊNCIAS}

ASPECT,A., DALIBARD, J. e ROGER, G., Phys. Rev. Lett, vol. 39, p. 1804,1982

BACHELARD, G., O novo espírito científico. Tradução: J. J. M. Ramos. São Paulo: Abril Cultural, 1984.

BEAUDE, J., "Mecanicismo, cap. V". In: Galileu, Descartes e o Mecanicismo. Lisboa: Gradiva, 1987.

BELL, J. S., Physics, vol. 1, p. 195, 1964.

BERGSON, H., Duração e simultaneidade [1922]. Tradução Cláudia Berliner. São Paulo: Martins Fontes, 2006.

BRAGA, R., A apercepção originária de Kant na Física do Século XX. Apresentação: H. C. Lima Vaz. Belo Horizonte: Editora da UFMG, 1991.

BUNGE, M., Filosofia da Física. São Paulo: Liv. Martins Fontes, 1973.

COPÉRNICO, N., Commentariolus, Rio de Janeiro: Edit. Nova Stella. Coppe. MAST, 152 pp, 1990.

CUNHA, M. O. T., Emaranhamento: caracterização, manipulação e consequências. Tese de doutorado. UFMG, 2005; Noções de Informação Quântica. 26 Colóquio Brasileiro de Matemática. Rio de Janeiro: IMPA, 2007. 
DAVIES, P. e BROWN, J. R., O Átomo Assombrado. Lisboa: Gradiva, 1991

EINSTEIN, A., PODOLSKI, B; ROSEN, N., Phys. Rev., vol. 47, p. $777-780,1935$

FERMI, E., PASTA, J. R. e ULAM, S.M., Studies of Nonlinear Problems. Los Alamos. Sci. Lab. Rep., LA-1940, 1955. Later published in Collected Papers of Enrico Fermi, edited by E. Segré, University of Chicago Press, v. 2, p. 978, 1965.

GARDNER, C.S., GREEN,J. M., KRUSKAL, M. D., MIURA, R. M., "Method for solving the Korteweg De Vries equation", Phys. Rev. Lett., v. 19, p. 1095 - 1097, 1967.

GEYMONAT, L., "Dialética científica e liberdade", In: Geymonat Ludovico, Giorello, G., As razões da ciência. Lisboa: Edições 70, 1986.

GILES, T. R., O que é Filosofar? 3a Ed. São Paulo: EPU, 55 p, 1984.

GITTERMAN, M., The Noisy Pendulum, London: World Scientifiic, 120 pp, 2008

HAGEDORN, N., Oscilações Não-Lineares. Tradução: N. Nascimento. São Paulo: Edgard Blücher Ltda, 320 pp, 1984.

HERBERT, N., A Realidade Quântica. Rio de Janeiro: Livraria Francisco Alves Editora, 1983. 
ISHAM, C. J., Lectures on Quantum Theory - Mathematical and Structural Foundations. London: Imperial College Press, 220 p, 1995.

KORTEWEG, D. J., and DE VRIES, G., "On the change of from long waves advancing in a rectangular channel, and on a new type of long stationary waves", Philos. Magazine, London, v. 39, n. 5, p. 442-443, 1895.

KUHN, T., A Estrutura das Revoluções Científicas. Coleção Debates: Edit. Perspectiva S.A., 264 pp, 9a Ed, 2006.

NEWTON, I., Principia - Princípios Matemáticos da Filosofia Natural. Coleção: Livros que mudaram o mundo. Folha de São Paulo: Levoir S.A., 121 pp, 2010.

NICOLIS, G., Exploring Complexity. San Francisco: Freeman, 1989.

OSADA, J., Evolução das ideias da Física. São Paulo: Editora da USP - Edgard Blücher, 1972

PATY, M., A matéria roubada: a apropriação crítica do objeto da Física Contemporânea. Tradução: M. A. Leite de Barros. São Paulo: Edusp, 320 pp, 1995.

PLANCK, M., The Theory of Heat Radiation. New York: DOVER, 1991

PINHO, S. T. R de e ANDRADE, R. F, S., "Evolução das ideias da Termodinâmica e da Mecânica Estatística. Cap. II", in: Origens e Evolução das Ideias da Física. (Org.) J. F. M. Rocha, Salvador: EDUFBA, pp. 139 - 184, 2011. 
POINCARÉ, H., Ensaios Fundamentais. Tradução: Vera Ribeiro, Rio de Janeiro: Contraponto - PUC - Rio, 2008.

PRIGOGINE, I. Do ser ao devir. Nomes de Deuses: Entrevistas a Edmond Blattchen. Tradução: Maria Leonor F. R. Loureiro: UNESP, 85 pp, 2002.

REDHEAD, M., Da Física à Metafísica: Edit. Papirus, 96 pp, 1997.

RIBEIRO FILHO, A., Os Quanta e a Física Moderna. Cap. V, in: Origens e Evolução das Ideias da Física. (Org.) J. F. M. Rocha, Salvador: EDUFBA, pp. 300 - 362, 2011.

RIBEIRO FILHO, A., e VASCONCELOS, D. S. de, "Aspectos matemáticos em sistemas não lineares na mecânica quântica $\mathrm{e}$ mecânica clássica modernas". Caderno de Ciências Humanas Especiaria, v. 9, n. 16, p. 397 - 410, 2006.

RUSSELL, J. S., "Report on Waves". Rep. $14^{\text {th }}$ Meet. British Association Adv. Sci., Edinburgh, p. 311 - 390, 1844.

SANTOS, M., Por uma outra globalização - do pensamento único à consciência universal, São Paulo: Editora Record, 2000.

SOMMERFELD, A., Mechanics. New York: Academic Press Inc, 1952.

TRAINOR, L. E. H., and WISE, M. B., "From physical concept to mathematical structure: an introduction to the theoretical physics". Mathematical Expositions n. 22, Toronto: University of Toronto Press, 399 pp, 1981. 
ZABUSKY, N. and KRUSKAL, M., "Interaction of solitons in a colisionless plasma and the recurrence of initial states". Phys. Rev. Lett, New York, v. 15, p. 240-243, 1965. 